\title{
- Patofisiologia e tratamento da pododermatite asséptica difusa nos equiiinos - (Laminite equiiina)
}

\section{Laminitis pathophysiology and treatment in horses}

* Armen'Thomassian ${ }^{1}$-CRMV-SPn ${ }^{0} 1113$

José Luiz de Mello Nicoletti ${ }^{2}$-CRMV-SP n ${ }^{0} 1081$

Carlos Alberto Hussni ${ }^{3}-$ CRMV-SP $n^{0} 4418$

Ana Liz Garcia Alves ${ }^{3}$ - CRMV-SP n 5776
* Faculdade de Medicina Veterinária e Zootecnia - UNESP Departamento de Cirurgia e Anestesiologia Veterinária Rubião Júnior - $s / n^{\circ}$ CEP: 18618-000-Botucatu-SP e-mail: thomassian@fmvz.unesp.br

1 Professor Titular de Cirurgia de Grandes Animais - FMVZ - UNESP Botucatu.

2 Professor Adjunto de Cirurgia de Grandes Animais - FMVZ - UNESP Botucatu.

3 Professores Assistentes Doutores de Cirurgia de Grandes Animais - FMVZ- UNESP Botucatu.

\section{RESUMO}

Por constituir-se em grave afecção que acomete o aparelho locomotor dos eqüinos, a pododermatite asséptica ou laminite é apresentada nesse trabalho, abordando-se, pormenorizadamente, os aspectos anatômicos do pé, a etiopatogenia, os sinais clínicos da fase aguda e crônica, assim como os principais procedimentos utilizados para o tratamento. São referidos procedimentos cirúrgicos modernos para abordagem dos casos clínicos mais graves ou refratários aos procedimentos conservativos.

Palavras-chave: eqüinos, aparelho locomotor, claudicação, laminite.

\section{Introdução}

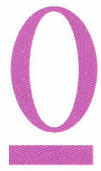
aparelho locomotor dos eqüinos, sem dúvida alguma, reveste-se de grande importância por constituir o sistema de sustentação e da dinâmica da locomoção nesta espécie. Desde a antigüidade, os mais conceituados "hipiatras" já consideravam que "sem pés não há cavalo", o que a rigor constitui-se no mais forte aforismo que define a gravidade das afecções que podem acometer o aparelho locomotor dos cavalos.

\section{Definição}

A pododermatite asséptica difusa (laminite) é uma doença que acomete os pés dos eqüinos, caracterizandose, principalmente, por alterações vasculares inflamatórias que se instalam nos tecidos laminares sensitivos.

Atualmente, em razão do melhor entendimento dos fenômenos etiopatogênicos que ocorrem na instalação do processo, a laminite é definida como uma desordem metabólica sistêmica que afeta os sistemas cardiocirculató- 
THOMASSIAN, A.; NICOLETTI, J. L. M.; HUSSNI, C.A.; ALVES, A.L.G. Patofisiologia e tratamento da pododermatite asséptica difusa nos eqüinos - (Laminite eqüina) / Laminitis pathophysiology and treatment in horses. Rev. educ. contin. CRMV-SP / Continuous Education Journal CRMV-SP, São Paulo, volume 3 , fascículo 2, p. $16-29,2000$.

rio, renal, endócrino, o equilíbrio hidroeletrolítico e a coagulação sangüínea, com manifestação principal nos cascos, culminando com a rotação da falange distal, em decorrência da redução da perfusão sangüínea, formação de "shunts" artério-venosos e trombose na circulação nutridora do estojo córneo.

\section{Estruturas anatômicas do casco}

Os cascos dos solípedes são compostos por três camadas:

\section{1 - Estrato externo \\ 2 - Estrato médio \\ 3 - Estrato interno}

O estrato externo é uma delgada camada córnea tubular, macia e escamosa, que se origina das camadas germinativas da epiderme do períoplo.

O estrato médio consiste em uma queratina tubular e intertubular, e constitui-se na principal estrutura de sustentação da parede. Os túbulos córneos estão orientados paralelamente à superfície externa do casco e suas células queratinizadas possuem uma disposição altamente ordenada.

O estrato interno é formado por aproximadamente 600 lâminas queratinizadas primárias, orientadas verticalmente e que se estendem para o interior do estrato médio, com o qual são contínuas. Cerca de 100 a 200 lâminas secundárias projetam-se em ângulos retos de cada lâmina primária. Essas lâminas interdigitam-se com lâminas semelhantes do córium e ancoram o casco queratinizado no tecido conjuntivo sensível adjacente.

A capacidade de um cavalo locomover-se adequadamente, entre outras características morfo-funcionais, depende da integridade do sistema de sustentação do casco, proporcionado pelo tecido podofiloso, perfeitamente interdigitado e composto pelo córion laminar, que ocupa o espaço entre as lâminas córneas do estrato interno da muralha do casco e a falange distal. Este sistema laminar de sustentação possui uma grande e delicada rede microvascular, responsável pela nutrição dos tecidos do pé e eliminação dos catabólitos provenientes da junção da lâmina epidérmica externa e da dérmica interna.

\section{Ocorrência}

A laminite ocorre apenas esporadicamente, entretanto, sob certas condições pode acometer vários animais, de uma mesma propriedade, submetidos às mesmas condições de criatório e manejo. Pode acometer com mais frequiência os dois membros torácicos e, até, os qua- tro membros nos casos mais graves, demonstrando manifestações clínicas características.

Dentre os eqüídeos, os pôneis são muito susceptíveis, com incidência até quatro vezes maior do que nos demais. Cavalos castrados são menos predispostos a desenvolver laminite, ao passo que animais na faixa etária de 4 a 10 anos estatisticamente apresentam maiores índices de laminite; assim como cavalos que são transportados e permanecem por vários dias em decúbito quadrupedal, sem alimentação e ingestão de água adequadas, podem desenvolver a forma aguda da laminite.

\section{Etiologia}

Muitas são as teorias aventadas para explicar a etiologia do processo, permanecendo, no entanto, uma série de dúvidas sobre a real compreensão dos fenômenos que envolvem o problema. As diversas causas de laminite podem ser classificadas como predisponentes e determinantes no desencadeamento da etiopatogenia, porém, a interação de fatores é que, na realidade, constitui-se a responsável pela instalação das lesões.

\section{A LAMINITEÉ UMA AFECÇÃO MULTIFATORIAL}

\section{As causas mais freqüentes de laminite são:}

\section{A - Alimentar (ingestão de carboidratos em exces-}

so): a quantidade de grãos necessária para desencadear o processo patogênico varia conforme o grau de tolerância do animal em ingerir este alimento. Cavalos que não recebem rotineiramente em seu manejo alimentar grãos ou rações concentradas com altos níveis de carboidratos, são particularmente susceptíveis de desenvolver graves quadros de laminite.

Com base no modelo experimental da laminite por ingestão excessiva de carboidratos, foram identificados fenômenos que promovem alterações no equilíbrio dos microorganismos do ceco. $\mathrm{O}$ excesso de ingestão de grãos ou de concentrados contendo altos níveis de carboidratos resulta em substancial elevação da quantidade de bactérias produtoras de ácido láctico (Streptococos sp; Lactobacilus sp). A elevação dos níveis de ácido láctico, e o conseqüente decréscimo do $\mathrm{pH}$, causa lise da parede das bactérias gram-negativas e libera a cadeia de lipopolissacarídeos, que se constituem em potentes endotoxinas com poderes vasoativos, que, ao atravessarem a barreira intestinal, alcançam a corrente sangüínea, desencadeando o quadro de laminite (Quadro 1). 
THOMASSIAN, A.; NICOLETTI, J. L. M.; HUSSNI, C.A.; ALVES, A.L.G. Patofisiologia e tratamento da pododermatite asséptica difusa nos eqüinos - (Laminite eqüina) / Laminitis pathophysiology and treatment in horses. Rev. educ. contin. CRMV-SP / Continuous Education Journal CRMV-SP, São Paulo, volume 3 , fascículo 2, p. $16-29,2000$.

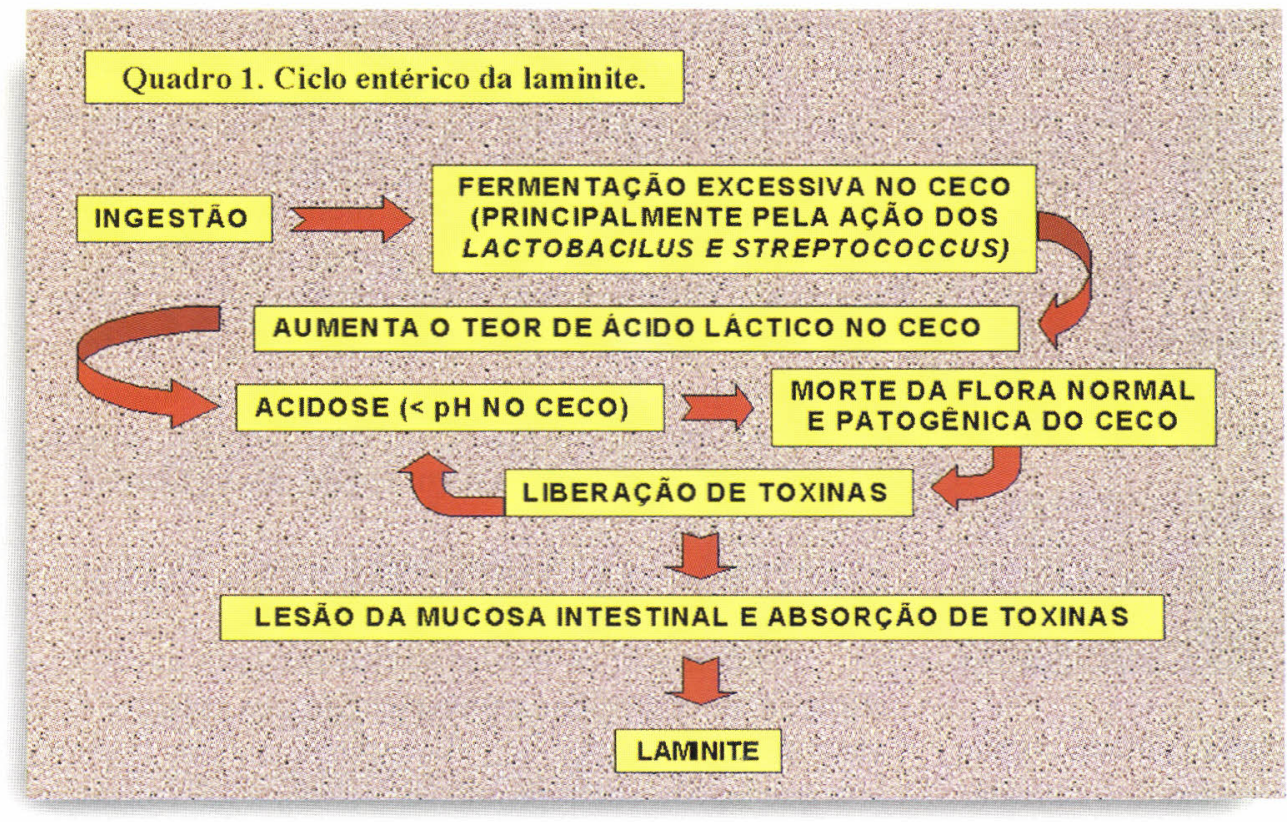

sem retenção de envoltórios fetais, potencialmente podem desenvolver severa laminite 24 a 48 horas após o trabalho de parto, mesmo que não desenvolvam infecção uterina; exigem, portanto, especial atenção por parte do médico veterinário.

\section{D - Ingestão de forragens e} obesidade: a laminite em eqüinos (pôneis) devida à ingestão de gramíneas nos períodos de verão pode ocorrer, notadamente, em pastos contendo trevos e alfafa, sendo pouco freqüente em outros tipos de capins.

Animais que desenvolvem laminite decorrente da in-

Embora a teoria histamínica seja antiga e tenha sido substituída pelos estudos sobre a endotoxemia como desencadeadora das alterações circulatórias, em geral acontece a associação do quadro de laminite clássica ao de indigestão ou gastroenterite. Nessas circunstâncias, ocorre a transformação da histidina, formada no processo de digestão dos grãos, em histamina com ação vasoativa no pé; muito semelhante ao que acontece nas laminites secundárias aos quadros de síndrome cólica de origem digestiva.

\section{B - Mecânica (transportes longos, trabalhos força-} dos ou caminhadas muito longas em terrenos duros): esta etiologia da laminite é resultante de impacto do casco em solos duros ou em trabalhos forçados e prolongados, causando concussão, com conseqüente processo inflamatório no tecido podofilamentoso. Na dependência da intensidade e da extensão do processo inflamatório, instalam-se no sistema laminar do casco os fenômenos inflamatórios da laminite.

Animais com baixo condicionamento físico ou com cascos proporcionalmente pequenos, com alterações de conformação e frágeis, são predispostos a esta etiologia da laminite. Cavalos com impotência funcional de apoio de um dos membros torácicos, quer por ferimentos nos pés, quer por fraturas, em geral podem acabar apresentando, após alguns dias, laminite no membro contralateral devida à intensa fadiga de apoio.

C - Infecciosa: as pneumonias, endometrites e outras infecções de caráter severo, causadas por bactérias, podem desencadear quadro de laminite devida à ação de suas endotoxinas. Éguas que apresentaram parto distócico, com ou gestão de gramíneas, em geral são animais obesos, e há suspeitas de interação com fatores relacionados aos níveis de estrógenos contidos no alimento volumoso fresco. Alguns estudos procuram relacionar, também, a ocorrência desta etiologia da laminite com as manifestações de hipotiroidismo prévio.

E - Mistas: muitos são os fatores que podem predispor ou desencadear a instalação da laminite, porém, quando não existem evidências da possível causa do processo, deve-se atentar à possibilidade da ocorrência inespecífica de desequilíbrios hormonais, alterações tróficas da falange distal e hipertensão arterial digital. Nestes casos, doses excessivas e tratamento prolongado com corticosteróides, em especial a dexametasona, ou o uso de derivados da fenilbutazona nas mesmas condições, podem predispor ao desencadeamento de laminite. Estudos dos efeitos dos esteróides na rede vascular digital demonstraram que os esteróides exógenos aumentam a resposta dos vasos digitais aos níveis circulantes de catecolaminas, produzindo também um efeito mineralocorticóide, que teoricamente poderia predispor ou agravar a ocorrência de edema na região.

\section{Etiopatogenia - (Quadro 2) Fenômenos locais}

Independentemente da etiologia desencadeante do quadro de laminite, as alterações que se instalam são decorrentes de complexo mecanismo patogênico que, em muitas de suas características, assemelha-se aos mecanismos intermediários do ciclo do choque e da coagulação intravascular disseminada (DIC). 
A lesão digital é resultante de dois mecanismos principais: mecanismo vasoativo e coagulopatia. Estes mecanismos produzem isquemia por redução da perfusão capilar no interior do casco. Estes fenômenos desencadeiam a abertura de "shunts" artério-venosos que desviam o fluxo de sangue para a circulação venosa proximal ao leito vascular do casco, agravando a isquemia. Tal resposta, fundamentalmente é desencadeada por hormônios vasoativos originários da supra-renal e da ação das endotoxinas circulantes. Não havendo pressão capilar suficiente, ocorre estase, coagulação do san-

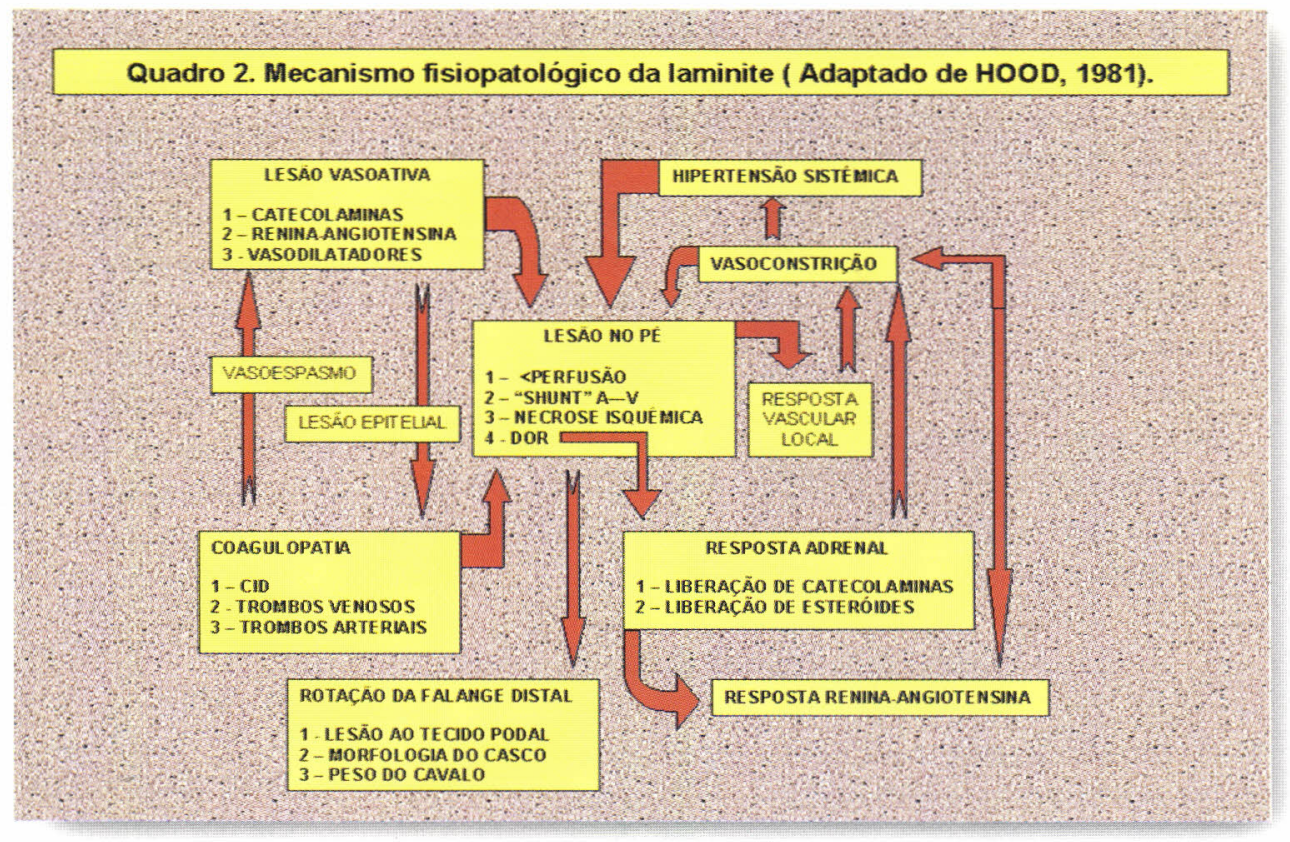

gue e aumento da permeabilidade vascular, ocasionando congestão e edema que se instala entre o pododerma e a epiderme, separando-os. O edema comprime os tecidos e agrava o quadro de hipoperfusão, que predispõe à formação de microtrombos, que, por sua vez, reduzem ainda mais a oferta de sangue aos tecidos, levando-os a processos de degeneração e morte. Teoricamente a ocorrência de intenso vasoespasmo pode resultar em lesão endotelial suficiente para promover a agregação de plaquetas e formação de trombos, assim como os agregados plaquetários no tromboembolismo causam a liberação de tromboxanas $\mathrm{A} 2$, que pode resultar em vasoespasmo, fechando o ciclo.

A dor, na fase aguda da laminite, é causada fundamentalmente em razão da isquemia, seguida da resposta inflamatória e de coagulação sangüínea. Estes fenômenos agem concomitantemente e desencadeiam as lesões de necrose isquêmica que se instalam no tecido podofiloso. As lesões que se estabelecem nos tecidos responsáveis pela nutrição e sustentação do casco, podem produzir o afundamento e a rotação da falange distal. O córion coronário palmar, a lâmina dérmica e o córion palmar da sola, não são comprometidos pelos fenômenos de isquemia por apresentarem intensa rede de vasos colaterais.

\section{Fenômenos sistêmicos}

Durante a fase aguda da laminite, podem ocorrer variados graus de hipertensão, taquicardia, moderada elevação dos níveis de lactato plasmático, moderada acidose metabólica e o hemograma revelar quadro característico de estresse.
O sistema endócrino apresenta elevações dos níveis sangüíneos de testosterona, cortisol, catecolaminas, da atividade da renina plasmática e depressão do funcionamento tireoideano. Ainda que a significância clínica seja desconhecida, estas alterações podem contribuir para a instalação de estado hipertensivo e de desequilíbrio hidroeletrolítico. Estas alterações metabólicas podem também predispor alguns animais a futuros episódios de laminite, com alto risco de recorrência.

A doença renal é um achado comum no cavalo com laminite crônica, predominando moderada glomerulonefrite membranosa, com significado clínico desconhecido, e necrose medular, que aparece como seqüela do uso de antiinflamatórios não-hormonais - inibidores da cicloxigenase (antiprostaglandínicos).

\section{Classificação e achados clínicos}

A laminite pode surgir como uma doença aguda, evoluindo para recuperação ou persistir em um estado crônico, ou pode desenvolver-se numa forma branda desde o início.

Tendo como base experimental o modelo de ingestão excessiva de carboidratos, HOOD (1989) classificou a laminite em:

\section{Quanto à evolução}

- Fase de desenvolvimento: inicia-se pela ação dos mediadores e outros fatores que desencadeiam o ciclo etiopatogênico até que o animal manifeste os primeiros sinais de claudicação - a manifestação é sub-clínica e pode durar entre 16 a 24 horas do início da ação do agente etiológico. 
THOMASSIAN, A.; NICOLETTI, J. L. M.; HUSSNI, C.A.; ALVES, A.L.G. Patofisiologia e tratamento da pododermatite asséptica difusa nos eqüinos - (Laminite eqüina) / Laminitis pathophysiology and treatment in horses. Rev. educ. contin. CRMV-SP / Continuous Education Journal CRMV-SP, São Paulo, volume 3, fascículo 2, p. 16 - 29, 2000.

- Fase aguda: inicia-se desde o momento em que o animal apresenta os primeiros sinais de claudicação até que ocorra o rebaixamento (afundamento) ou a rotação da falange distal.

- Fase crônica: inicia-se com o rebaixamento (afundamento) ou a rotação da falange distal, ou deve ser considerada quando o quadro de dor intensa perdurar por mais de 48 horas de forma contínua. Os fenômenos de rebaixamento ou rotação da falange distal poderão ocorrer precocemente desde a $24^{\mathrm{a}}$ hora do início do quadro de claudicação, que, na fase crônica, poderá caracterizar-se por intermitência e dar a nítida impressão clínica de agudização do processo.

\section{Quanto à apresentação}

1 - Laminite aguda: caracteriza-se, em geral, pelo aparecimento brusco dos sintomas, podendo acometer ambos os membros torácicos ou os quatro membros, predominando os sinais de locomoção penosa e lenta devida à dor. Quando ambos os membros torácicos estão comprometidos, o cavalo adota atitude antiálgica patognomônica, com extensão dos torácicos, apoio sobre os talões, avanço dos pélvicos, deslocamento do eixo de gravidade para trás, dando-se a impressão de que irá cair "sentado". O cavalo fica com uma base de apoio muito estreita, concentrando seu eixo de gravidade, o que exige um intenso trabalho dos músculos abdominais e dorsais (Figura 1).

O padrão de comportamento locomotor do cavalo com laminite na forma aguda pode ser classificado em 4 graus e reflete a gravidade dos fenômenos decorrentes das alterações da microcirculação do pé. Segundo OBEL

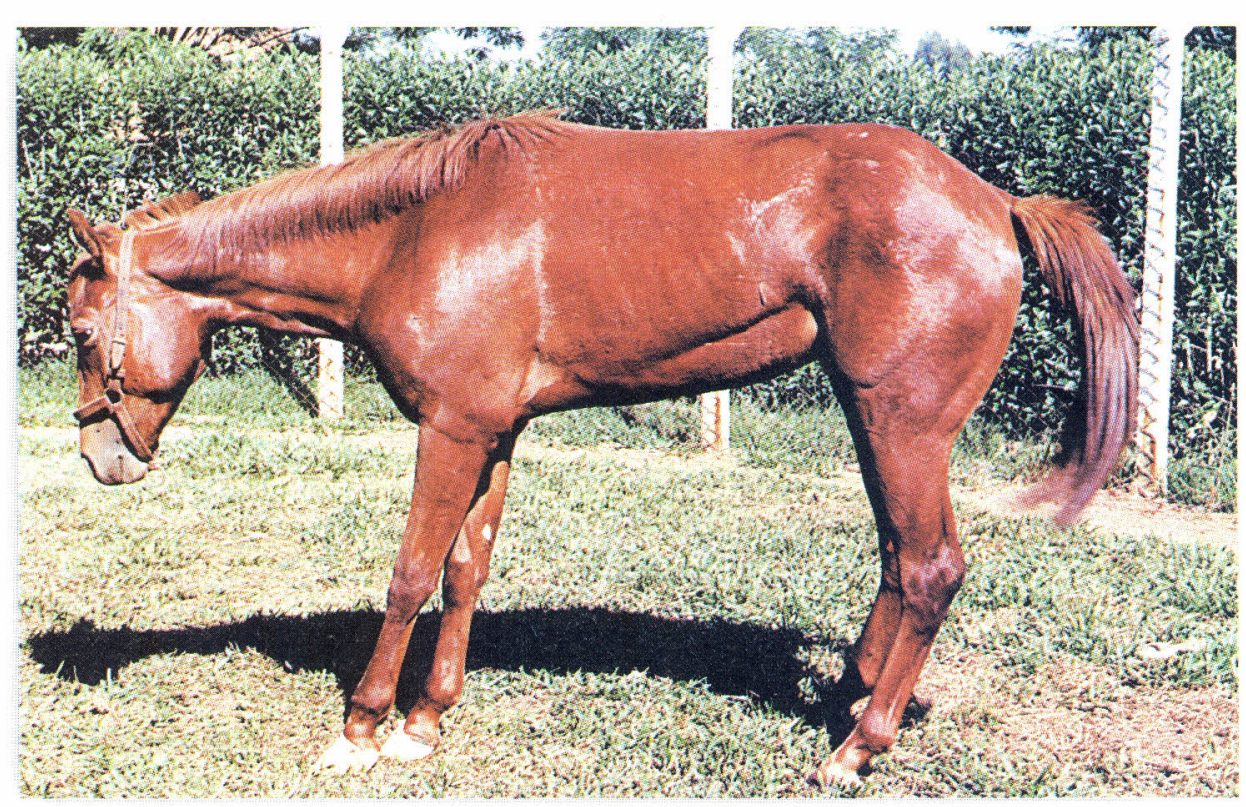

Figura 1. Posição patognomônica do corpo do cavalo com laminite.
(1948), a claudicação nos quadros de laminite aguda pode ser caracterizada e classificada em:

- Grau I: em repouso, o cavalo levanta os membros torácicos alternadamente e de forma incessante em intervalos de poucos segundos. A manqueira é imperceptível e observa-se, apenas e tão-somente, um encurtamento da primeira fase da locomoção; o animal retira rapidamente o membro de apoio no solo. Cada membro, toda vez que é elevado, volta a ser apoiado rapidamente, e assim sucessivamente. Este grau de claudicação pode se apresentar nas fases finais de desenvolvimento etiopatogênico ou no início da fase aguda.

- Grau II: o cavalo movimenta-se voluntariamente embora apresente um encurtamento mais evidente da fase de apoio do passo - marcha, característica da laminite. Neste grau, ainda é possível erguer-se um dos membro torácicos, em "mão de amigo", sem muita relutância por parte do animal.

- Grau III: o cavalo apresenta evidente relutância para iniciar a marcha e reage energicamente a qualquer tentativa de erguer-se qualquer membro.

- Grau IV: o cavalo somente inicia a locomoção quando forçado energicamente e, ao fazê-lo, em geral, projeta ambos os membros torácicos para cima e para frente, ficando apoiado por alguns momentos apenas sobre os membros pélvicos. Este tipo de movimento pode acarretar sérios acidentes à pessoa que esteja segurando a guia do cabresto e postada defronte ao animal.

Embora não tenha sido referido na classificação de OBEL (1948), por não ser propriamente uma condição de locomoção, animais com severo e rápido acometimento do sistema da microcirculação do casco, assim como de alterações metabólicas sistêmicas, decorrentes do desencadeamento etiopatogênico, podem permanecer em decúbito lateral durante longos períodos do dia, ou mesmo durante o dia inteiro. É evidente que essa situação irá predispor o animal ao agravamento de seu quadro clínico ou a severas escaras de decúbito.

A par das manifestações locomotoras do quadro de laminite aguda, o cavalo pode apresentar-se ansioso, com conjuntivas congestas, com taquipnéia e taquicardia, temperatura corporal até cerca de $40^{\circ} \mathrm{C}$ 
e tempo de perfusão capilar acima de 2 segundos. O pulso das artérias digitais estará cheio e forte. Os cascos apresentam-se quentes, especialmente junto à banda coronária, e sensíveis à percussão e pressão com a tenaz junto ao ápice da ranilha. Muitas das manifestações clínicas sistêmicas são decorrentes da dor e das alterações metabólicas gerais, podendo desencadear tremores musculares e a instalação de acidose metabólica. No casos mais graves, e ainda na fase aguda, em graus mais avançados da laminite, onde o edema é intenso e foi capaz de provocar intensa isquemia na região da coroa do casco, com necrose tecidual precoce, poderá haver descolamento da banda coronária com exsudação sangüinolenta, predispondo a instalação de microorganismos e transformar o processo asséptico em séptico. O edema e a necrose isquêmica no tecido podofiloso podem produzir, na fase final da forma aguda, o rebaixamento da falange, caracterizado pelo aparecimento de sulco em toda a extensão da banda coronária, ou possibilitar o processo de rotação da falange distal (Figura 2).

Os quadros clínicos brandos - subagudos - podem exibir alguns ou todos os sinais clínicos referidos para o quadro agudo, que podem tornar-se recidivantes ou evoluir para a forma crônica.

2 - Laminite crônica: A forma crônica da laminite advém da evolução de uma laminite aguda não tratada ou que foi tratada tardiamente, ou, ainda, cujo tratamento foi ineficiente para reverter o processo congestivo que se instalou. O processo pode tornar-se crônico após 48 horas de dor intensa e contínua ou com o início da rotação da falange distal. A claudicação pode ser mais branda nesta fase em razão da redução progressiva da dor devida à necrose isquêmica instalada. Ocasionalmente, alguns casos de laminite sob a forma crônica podem apresentar recorrência aguda, com exacerbação dos sinais clínicos locais e sistêmicos.

Em virtude das alterações circulatórias que se instalam na microcirculação do pé, em particular na banda coronária, onde a redução do fluxo sangüíneo traz como consequiência modificações no "status" do metabolismo queratogênico, ocorrem alterações na forma do casco (dismorfose), caracterizadas por formações de crescimento córneo irregular, chamados anéis de laminite, que podem ser observados evoluindo da região da coroa até a pinça e afastando-se uns dos outros na região dos talões. Os fenômenos de rebaixamento e rotação da falange distal agravam o comprometimento dos vasos circunflexos e da coroa do casco, causando a deformidade do estojo córneo. O casco, por si só, torna-se estreito e alongado, a sola torna-se convexa, ocorre o

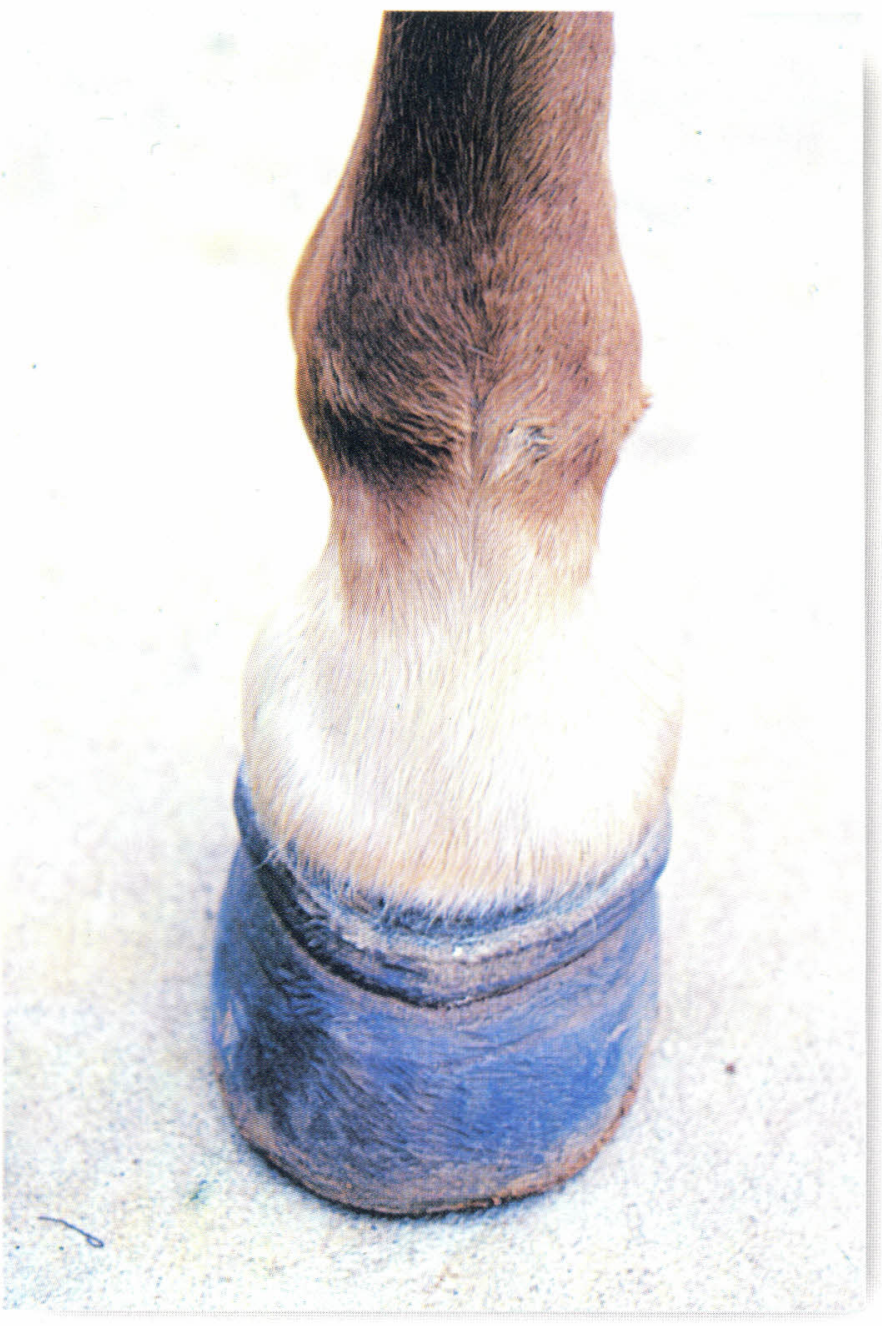

Figura 2. Rebaixamento da falange distal - formação de sulco acima da região da coroa do casco.

crescimento exagerado dos talões e forma-se concavidade acentuada da face crânio-dorsal da muralha (Figuras 3 e 4). O casco adquire o aspecto de "sapato chinês". Em graus avançados de rotação da falange distal, pode-se observar solução de continuidade da sola, transversalmente ao ápice da ranilha, correspondendo à necrose da sola, e, ocasionalmente, a exteriorização da pinça da falange, o que pode transformar o processo em séptico (Figuras 5 e 6). Na dependência do grau de rotação e da compressão da borda da falange distal no córion solear, poderá haver o desenvolvimento de osteíte rarefaciente com perda acentuada do arcabouço mineral do osso.

Concomitantemente à evolução dos sinais de deformidade do estojo córneo e ao abrandamento da sensibilidade dolorosa na região anterior ao ápice da ranilha, ocorre redução na intensidade dos sinais clínicos gerais, da amplitude do pulso das artérias digitais e da temperatura do casco. 


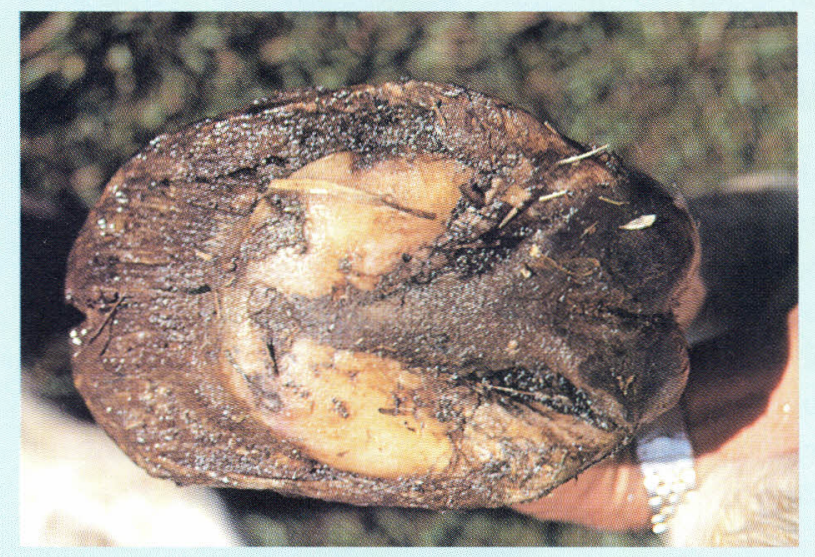

Figura 3. Convexidade da sola na laminite crônica.

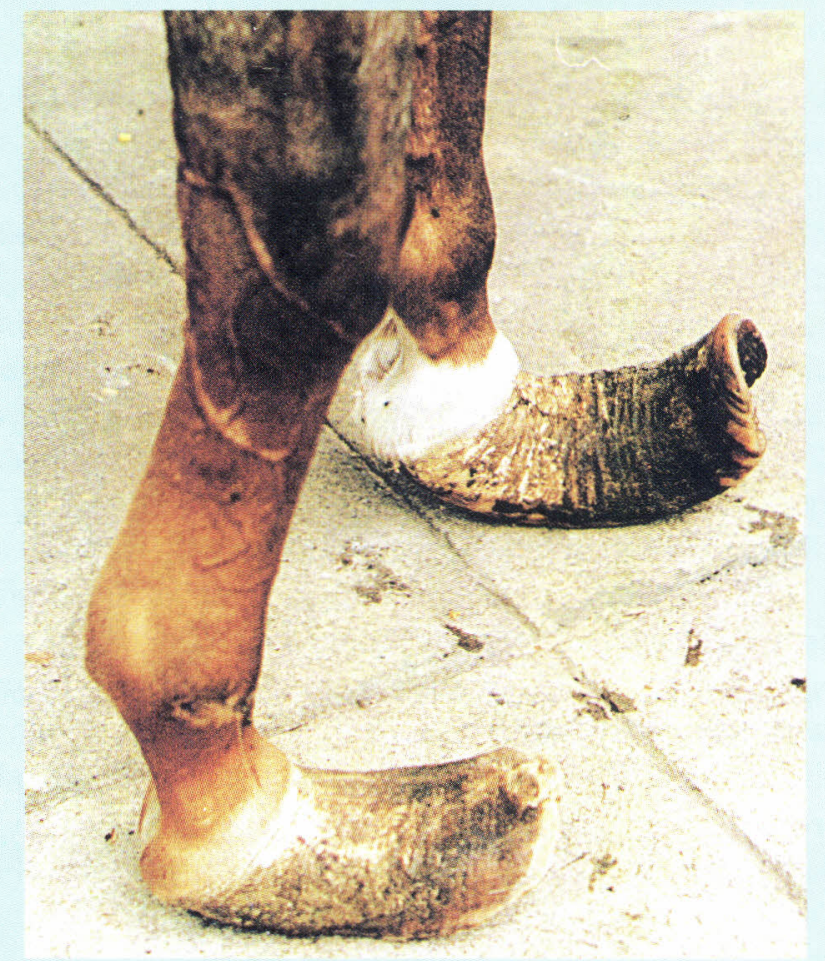

Figura 4. Crescimento anormal dos cascos na laminite crônica ("sapato chinês").

Baseando-se nas manifestações motoras, na dor e na possibilidade da instalação de infecção podal, a laminite crônica pode ser classificada em:

- Grau I: presença de dor, sem evidência de comprometimento acentuada na locomoção;

- Grau II: redução da dor, com comprometimento evidente da locomoção;

- Grau III: presença de dor e comprometimento da locomoção, sem evidência de infecção podal;

- Grau IV: comprometimento da locomoção e evidência de infecção podal, sem manifestação patente de dor;
- Grau V: presença de dor, dificuldade de locomoção, infecção e decúbito lateral prolongado.

Podem-se observar escaras de decúbito por sobre as tuberosidades ilíacas e olecranianas nos cavalos em decúbito, assim como intensa linha de hipertrofia da musculatura dos músculos oblíquo abdominais devida aos esforços em manter o eixo de gravidade do corpo.

\section{Diagnóstico}

O diagnóstico da laminite é baseado na avaliação rigorosa dos sinais clínicos podais e gerais. Entretanto, o grau de comprometimento metabólico, necessário para o acompanhamento da evolução de cada caso e a instituição de tratamento adjuvante específico, bem como a elaboração do prognóstico, devem ser acompanhados por rigoroso estudo radiográfico e exames laboratoriais para a detecção de possíveis infecções crônicas, doenças hepáticas, renais, gastrentéricas e cardiovasculares.

A laminite eqüina subclínica ou subaguda pode passar facilmente despercebida, a menos que haja uma história que possa indicar possíveis condições predisponentes e determinantes da afecção. Situações como manejo inadequado, infecções latentes e partos distócicos, entre outras possíveis causas, devem sempre chamar a atenção do clínico, durante a avaliação do caso.

A observação dos sinais clínicos torna o diagnóstico da laminite relativamente fácil de ser formulado. A postura corpórea típica do animal em repouso e locomoção, o aumento das freqüências respiratória e cardíaca; conjuntivas congestas; tempo de perfusão capilar alterado; aumento do pulso das artérias digitais e da temperatura do casco; linhas de laminites; deformidades do estojo córneo e sensibilidade ao teste da tenaz do casco são razões mais do que suficientes para considerar o diagnóstico como sendo laminite.

Além de constituir-se em procedimento antiálgico que pode ser utilizado no tratamento da laminite, o bloqueio dos nervos digitais palmares, junto à base dos sesamóides proximais, produz um pequeno alívio da sensação dolorosa, principalmente na forma aguda da afecção.

É de fundamental importância que sejam realizados estudos radiográficos nas diversas fases da abordagem de um animal portando quadro de laminite, independente da apresentação e evolução do processo. A imagem radiográfica poderá determinar a institui- 
THOMASSIAN, A.; NICOLETTI, J. L. M.; HUSSNI, C.A.; ALVES, A.L.G. Patofisiologia e tratamento da pododermatite asséptica difusa nos eqüinos - (Laminite eqüina) / Laminitis pathophysiology and treatment in horses. Rev. educ. contin. CRMV-SP / Continuous Education Journal CRMV-SP, São Paulo, volume 3, fascículo 2, p. $16-29,2000$.

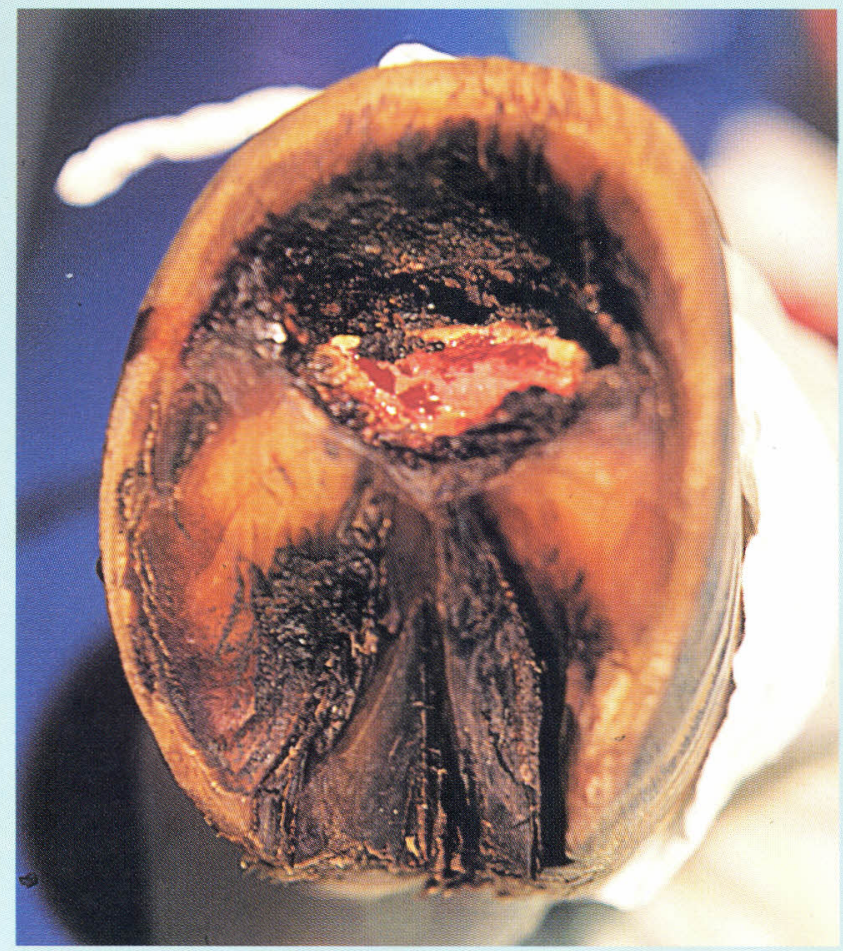

Figura 5. Perfuração da sola com exteriorização da pinça da falange distal na laminite crônica.

ção de tratamento mais agressivo ou definir o prognóstico do caso. Radiograficamente a rotação da falange distal é observada pela perda do paralelismo entre a face dorsal da falange e a muralha do casco (Figuras 7 e 8). Em todos os casos deverão ser tomadas radiografias periódicas na posição látero-medial, a cada 48 ou 72 horas do início da laminite aguda, para monitorar a progressão da falange distal. Sob o ponto de vista radiográfico, a laminite pode ser classificada em 5 categorias:

- $1^{\text {a }}$ : sem observação de anormalidades;

- $2^{\mathrm{a}}$ : deslocamento ventral da falange distal (rebaixamento);

- $3^{\mathrm{a}}$ : rotação da falange distal (diversos graus);

- $4^{\mathrm{a}}$ : rotação e rebaixamento da falange distal;

- $5^{\mathrm{a}}$ : rotação da falange distal com alterações ósseas secundárias crônicas.

\section{Prognóstico}

Além dos aspectos relativos às condições sistêmicas e podais do cavalo portador de pododermatite asséptica difusa ou pododermatite séptica que não responderam aos diversos recursos terapêuticos, sejam eles conservativos ou cirúrgicos, o grau de rotação constitui-se

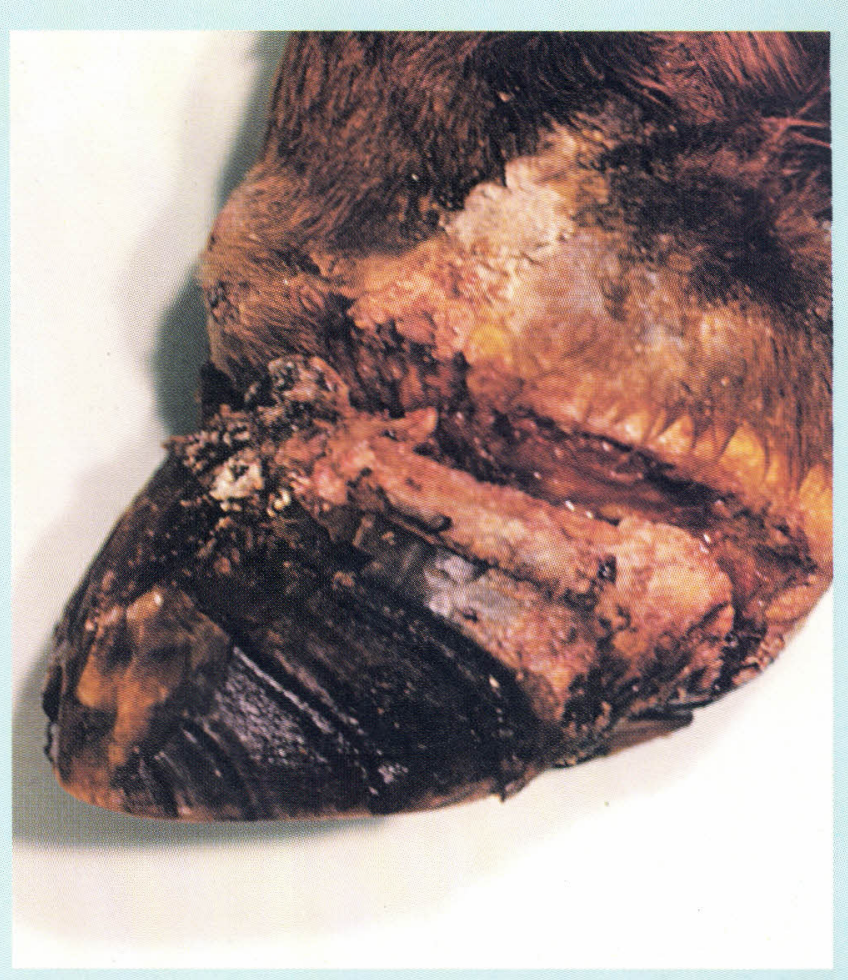

Figura 6. Pododermatite séptica decorrente de descolamento da coroa do casco - exungulação iminente.

em excelente indicador das possibilidades de recuperação de cavalos com laminite crônica. Assim sendo, devemos considerar:

\section{- Grau I: menores ou iguais a 5,5: prognóstico favorável;}

- Grau II: entre 6,8 a 11,5: prognóstico reservado;

- Grau III: maiores do que 11,5: prognóstico desfavorável.

É evidente que tais prognósticos devem sempre ser firmados à luz dos quadros clínicos e das respostas às terapias instituídas. Para tanto, estima-se que os cavalos com grau I de rotação da falange distal podem retornar à performance atlética anterior; grau II, retornam à atividade atlética, porém com performance pior do que antes do processo; grau III, os cavalos apresentarão claudicação persistente e jamais irão recuperar a performance normal.

\section{Tratamento}

O tratamento da laminite exige do médico veterinário, do proprietário do animal e do pessoal de enfermaria, consciência da gravidade do caso, conhecimento dos 


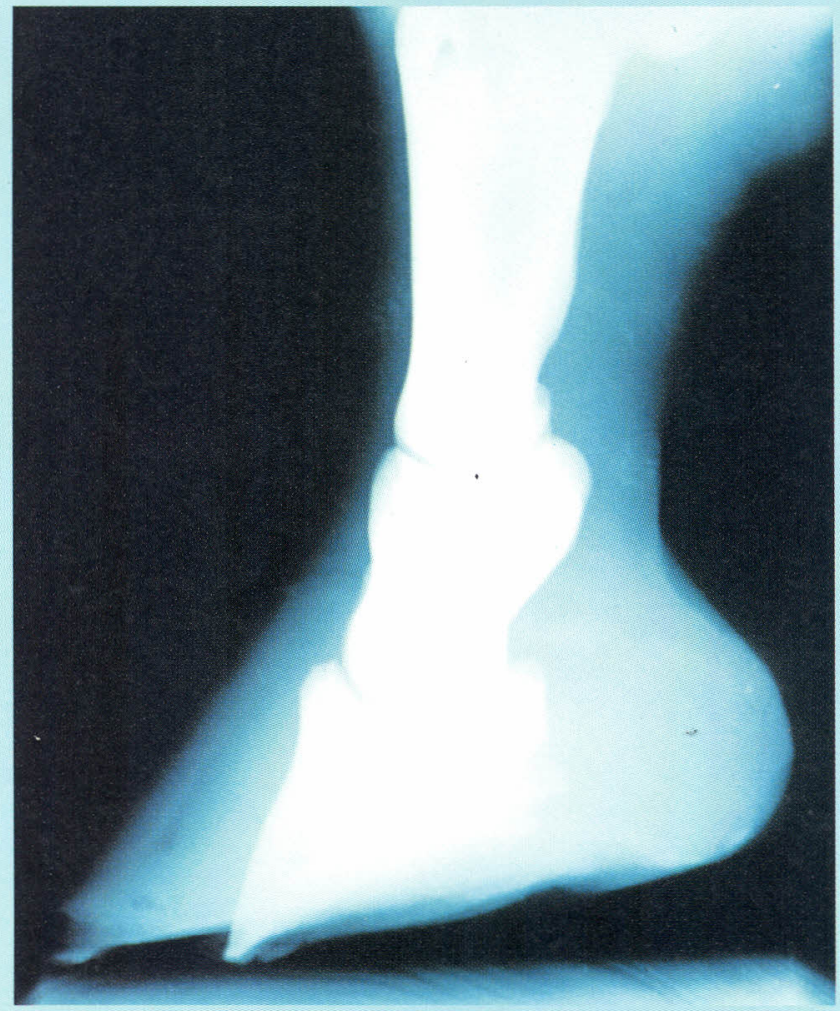

Figura 7. Rotação e exteriorização da pinça da falange distal.

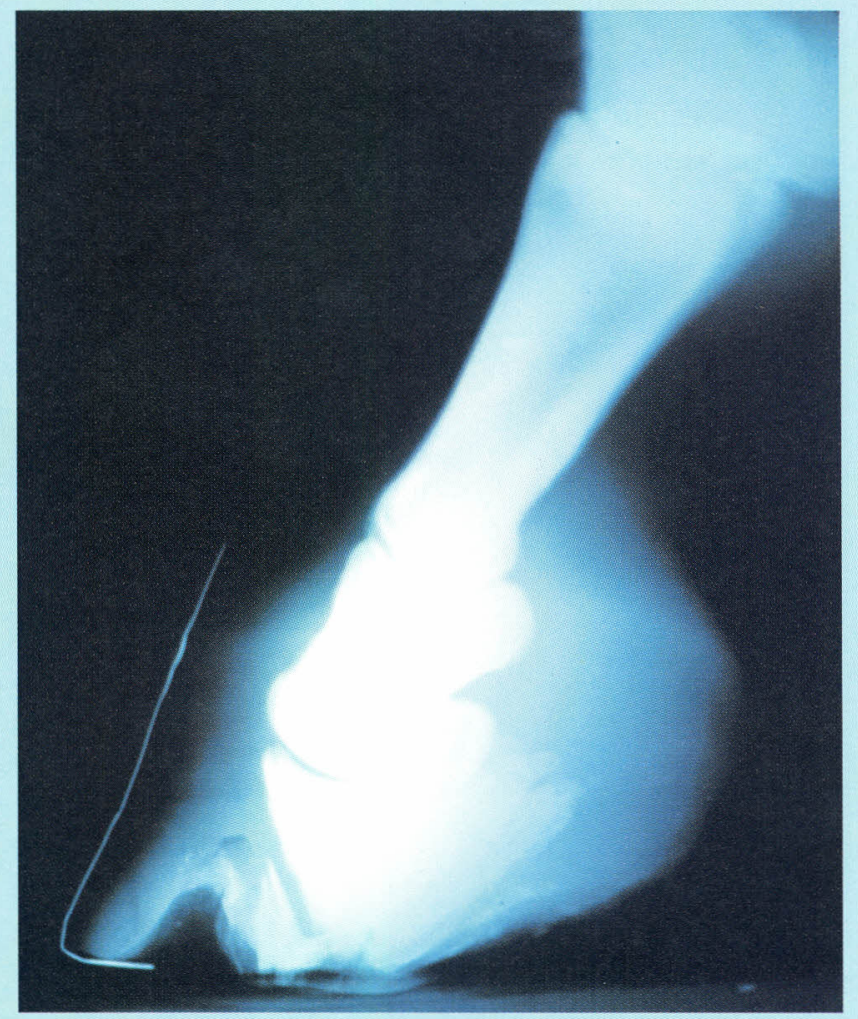

Figura 8. Rotação com exteriorização e fratura da pinça da falange distal.

\section{Hipotensores}

Ainda objetivando a redução da pressão arterial, pode-se lançar mão de bloqueadores alfa-adrenérgicos como:

- Cloridrato de acepromazina - na dose de $40 \mathrm{mg}$ totais, pela via IM ou IV, por um período de 24 a 72 horas; ou 0,02-0,05 mg/kg, pela via IM 3 vezes ao dia;

- Cloridrato de fenoxibenzamina - na dose de $2 \mathrm{mg} /$ $\mathrm{kg}$ de peso, divididos em 2 aplicações, injetadas, lentamente, pela via IV, em intervalos de 2 horas;

- Isoxisuprina - possui ação beta-agonista e pode ser aplicada na dose de 0,4 a $1,2 \mathrm{mg} / \mathrm{kg}$ de peso, pela via IM, 2 vezes ao dia, até a remissão dos sintomas;

- Furosemide - pode ser usado apenas na fase crônica da laminite, 1 a $3 \mathrm{mg} / \mathrm{kg}$ de peso, via IM/IV, 2 vezes ao dia.

\section{Anti-histamínicos}

Atualmente, acredita-se que estas drogas não sejam eficazes porque atuariam sobre os receptores alfa podais, não possuindo eficácia sobre a produção ou a his- 
tamina já liberada na corrente sangüínea. Entretanto, na fase de desenvolvimento do quadro de laminite, em particular sob esquema preventivo em éguas que tiveram parto distócico ou retenção placentária, certamente apresentam efeitos terapêuticos satisfatórios.

Promazina: 0,4 a 1,0 mg/kg de peso, via IM/IV, uma vez ao dia, por 3 a 5 dias.

\section{Antiinflamatórios não esteroidais}

Objetiva principalmente a remissão da dor que se constitui em importante estimulador simpático, agravante da hipertensão, da formação de "shunts" artério-venosos e da vaso constrição podal. Atuam inibindo, ainda, principalmente os efeitos pró-inflamatórios das prostaglandinas, das cininas e do tromboxane A2.

\section{- Fenilbutazona:}

$4,4 \mathrm{mg} / \mathrm{kg}$ de peso, via IV, 2 vezes ao dia, no $1^{\circ}$ dia. $2,2 \mathrm{mg} / \mathrm{kg}$ de peso, via IV, 2 vezes ao dia, no $2^{\circ}$ dia. $2,2 \mathrm{mg} / \mathrm{kg}$ de peso, via PO, $1 \mathrm{vez}$ ao dia, por tempo a ser determinado pelo clínico ( $<10$ dias).

\section{- Flunixim meglumine:}

$1,1 \mathrm{mg} / \mathrm{kg}$ de peso, vias IM/IV, 3 vezes ao dia, no $1^{\circ} \mathrm{dia}$. $1,1 \mathrm{mg} / \mathrm{kg}$ de peso, vias IM/IV, 2 vezes ao dia, por 5 a 7 dias. $0,25 \mathrm{mg} / \mathrm{kg}$ de peso, via IM, 3 vezes ao dia, nos casos de intensa endotoxemia, como a que ocorre nas laminites de origem alimentar.

- Ácido acetilsalicílico: além de atividade anti-prostaglandina, o AAS possui potente ação anti-agregadora plaquetária, prevenindo a formação de trombos. 4-20 mg/kg, PO, 2 vezes ao dia.

\section{Anticoagulantes}

- Heparina (doses mais utilizadas): monitorar tempo de protrombina.

doses altas -40 a $100 \mathrm{UI} / \mathrm{kg}$, via SC, 4 vezes ao dia. doses baixas $-100 \mathrm{UI} / \mathrm{kg}$, via IV, 2 vezes ao dia, ou 80 $\mathrm{UI} / \mathrm{kg}$ de peso, via IV, seguida por $160 \mathrm{UI} / \mathrm{kg}$ de peso, via $\mathrm{SC}$, duas vezes ao dia.

\section{Outros procedimentos conservativos}

- Dimetilsulfóxido (DMSO): ação antiinflamatória, analgésico, anti-agregador plaquetário e vasodilatador, entre outras, podendo ser utilizado concomitantemente a outras drogas.

Dose: $100 \mathrm{mg} / \mathrm{kg}$ de peso, diluídos em solução de glicose na concentração a $10 \%$, infusão lenta, 2 vezes ao dia, por 2 dias.
- Cimetidine: antagonista $\mathrm{H} 2$ na dose de $18 \mathrm{mg} / \mathrm{kg}$ de peso, via IM, a cada 4-6 h, ou associada à tripenelamida na dose de $1,0 \mathrm{mg} / \mathrm{kg}$ de peso a cada $8 \mathrm{~h}$.

- Anestesia dos nervos digitais: é utilizada para aliviar a sensação de dor e melhorar a circulação local, permitindo que o animal se locomova com certo conforto. O bloqueio dos nervos digitais auxilia na manipulação semiológica dos membros e no ferrageamento do cavalo com laminite.

- Óleo mineral: nos casos em que a etiopatogenia da laminite seja decorrente de causas alimentares, especialmente por ingestão de excesso de carboidratos, a administração de cerca de 2 a 4 litros de óleo mineral, uma única vez, através da sonda nasogástrica, reduz drasticamente a absorção de toxinas e, conseqüentemente, a intensidade das manifestações clínicas.

\section{2 - Físicos}

\section{Duchas e pedilúvios}

O tratamento da laminite na fase aguda pode ser iniciado com aplicações de duchas frias sobre o pé do cavalo, pelo menos 3 vezes ao dia, durante 20 minutos cada aplicação. Em situações de extrema gravidade, podese instituir pedilúvios com água e gelo, também 3 vezes ao dia, por no máximo 10 a 15 minutos cada tratamento, controlando-se sempre a temperatura da água em torno de $10^{\circ} \mathrm{C}$, e evitando-se o contato do gelo diretamente sobre a pele do animal. Durante a fase crônica, as duchas ou pedilúvios frios podem ser intercaladas com duchas ou pedilúvios mornos.

\section{Exercícios}

O exercício melhora o fluxo sangüíneo indiretamente, permitindo o "bombeamento" do sangue venoso. Preferencialmente o exercício constará de caminhadas ao passo em terreno macio (areia) ou gramado alto. É preciso estimar-se que, nos casos mais graves, o exercício pode potencializar a sensação álgica e agravar as forças mecânicas que atuam sobre a falange distal, fazendo com que ocorra a rotação, ou agravando-a quando em graus discretos.

\section{Gessamento do pé}

Além de proteger a sola do contato direto com o solo, o que aumentaria a dor, o gessamento do casco pos- 
THOMASSIAN, A.; NICOLETTI, J. L. M.; HUSSNI, C.A.; ALVES, A.L.G. Patofisiologia e tratamento da pododermatite asséptica difusa nos eqüinos - (Laminite eqüina) / Laminitis pathophysiology and treatment in horses. Rev. educ. contin. CRMV-SP / Continuous Education Journal CRMV-SP, São Paulo, volume 3, fascículo 2, p. $16-29,2000$

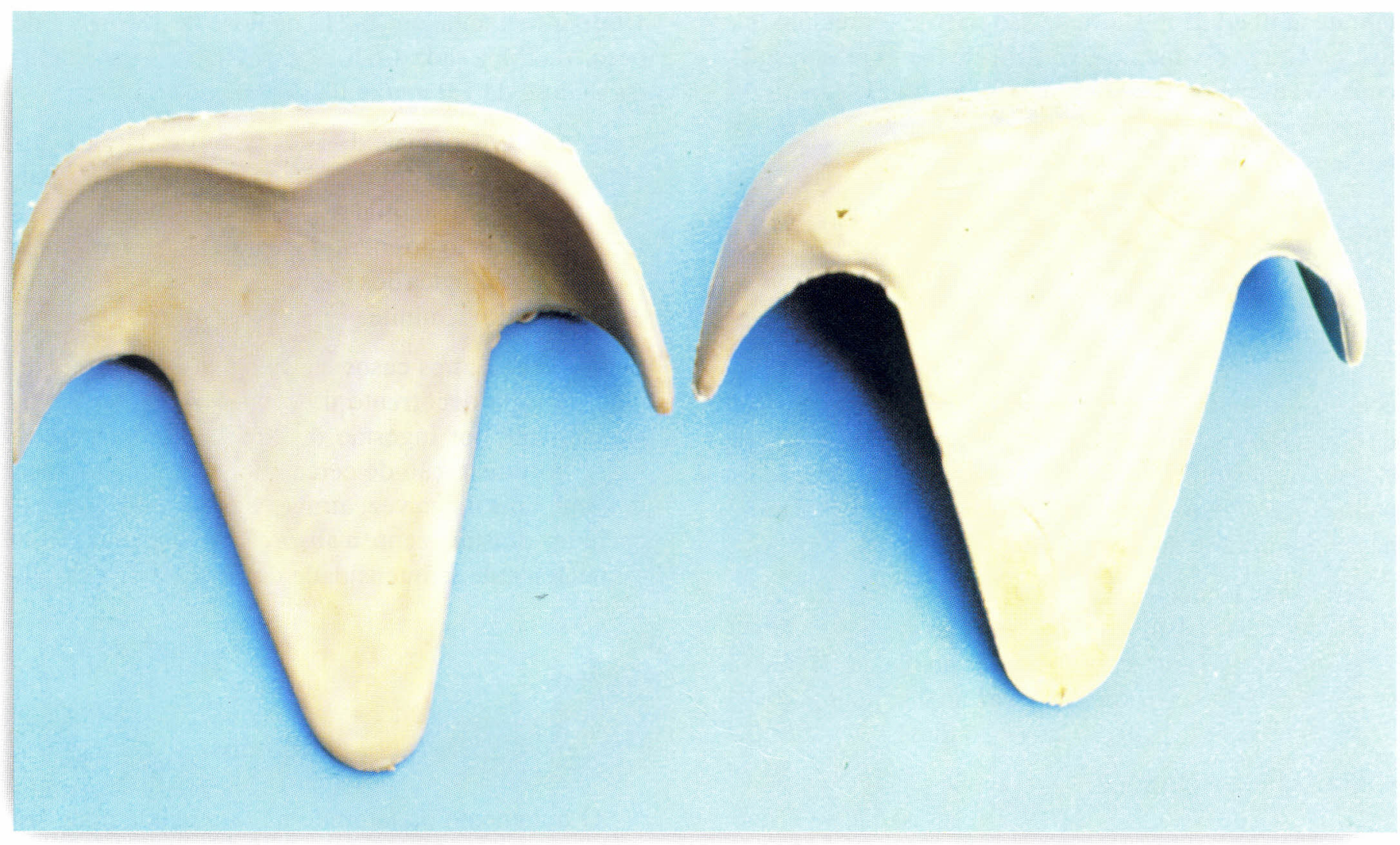

Figura 9. Palmilha ortopédica de pressão da ranilha.

sibilita o apoio para a falange, contribuindo para que esta se mantenha em posição anatômica e auxilie o fluxo sangüíneo podal. Na fase aguda, o gessamento do casco proporciona alívio imediato ao cavalo, reduzindo os efeitos adrenérgicos da dor. O gessamento do pé do cavalo deve ser realizado preenchendo-se, previamente, o espaço correspondente à sola e os sulcos da ranilha, com duas ou três camadas de faixas gessadas, que podem ter $10 \mathrm{~cm}$ de largura.

\section{Palmilha}

Assim como o gessamento, a palmilha tem por finalidade proporcionar apoio para a ranilha, possibilitando que haja atividade do aparelho fibroelástico do casco com expansão e "bombeamento" do sangue venoso. O uso das palmilhas também proporciona alívio ao cavalo, principalmente quando utilizada na fase aguda da laminite (Figura 9).

\section{Ferrageamento}

Os objetivos do ferrageamento em cavalos com laminite são: proteger as áreas dolorosas da sola e parede do casco do contato com o solo; prevenir a lesão tecidual e a rotação da falange distal; fornecer suporte para os pés; proporcionar condições de reparação do dígito e facilitar a dinâmica do passo. Dentre as ferraduras para cavalos com laminite, podem ser indicadas a "heart-bar shoes" (Figura 10) e a "egg-bar shoes" como as mais utilizadas e, mais recentemente, as ferraduras autocolantes. "Ferraduras rolantes" (pinça quadrada) possibilitam que a primeira fase do passo seja realizada sem aumento de tensão sobre o tendão flexor digital profundo, menor pressão sob a terceira falange e, conseqüentemente, redução da dor. Ocasionalmente, ferraduras "heart-bar-shoes" reguláveis, podem intensificar a dor aumentando consideravelmente o desconforto do cavalo.

Cavalos que se encontram com ferraduras quando do desencadeamento da laminite, devem ter estas apenas afrouxadas nas primeiras 12 - 24 horas de evolução, para posteriormente serem retiradas.

\section{3 - Cirúrgico}

\section{Casqueamento e ressecção da muralha}

O casqueamento pode ser feito em cavalos com laminite crônica, além dos demais procedimentos médi- 
THOMASSIAN, A.; NICOLETTI, J. L. M.; HUSSNI, C.A.; ALVES, A.L.G. Patofisiologia e tratamento da pododermatite asséptica difusa nos eqüinos - (Laminite eqüina) / Laminitis pathophysiology and treatment in horses. Rev. educ. contin. CRMV-SP / Continuous Education Journal CRMV-SP, São Paulo, volume 3, fascículo 2, p. $16-29,2000$.

cos e físicos já mencionados. O casqueamento está voltado para a correção das deformidades do estojo córneo, com a retirada radical de todo tecido excedente mortificado, procurando-se proporcionar o paralelismo da falange distal com a muralha do casco (Figura 11). É comum observar-se no tecido podofiloso mortificado a presença de sangue "liofilizado" entre as lamínulas da muralha do casco. O casqueamento "rolante" (pinça quadrada) poderá também ser realizado com o mesmo objetivo de dinâmica locomotora adotada para o "ferrageamento rolante".

Os talões não devem ser rebaixados abruptamente, a um só tempo. Deve-se retirá-los paulatinamente, à medida que o quadro clínico apresente melhora. O rebaixamento abrupto dos talões poderá agravar a rotação da falange distal, aumentando a tensão sobre a mesma. Quando radiograficamente for constatada a manutenção do eixo falangeano, o profissional deve evitar, ao menos nas fases iniciais do tratamento, o rebaixamento dos talões.

A ressecção da muralha do casco, além de estar indicada para os casos crônicos, com grandes deformidades dos cascos, também poderá ser indicada no início do processo, quando ainda estão presentes alguns sinais locais da fase aguda, sem que o casco apresente deformidades características do processo crônico (Figura 12). A ressecção da muralha, além de aliviar a dor, reduzindo a pressão no interior do casco, possibilita a reacomodação da falange distal em graus discretos de rotação.

\section{Tenotomia do flexor digital profundo}

Alguns cavalos com laminite crônica, com rotação da falange distal dos membros torácicos, e que não responderam aos procedimentos corretivos, como última opção, podem ser submetidos à tenotomia do flexor digital profundo, na região dorsal à inserção do ligamento acessório do carpo. Este procedimento cirúrgico irá aliviar a dor e possibilitar o reposicionamento da falange distal.

\section{Fresamento da sola}

Indicada para os casos de rotações acima de 6,8 graus e em cavalos com exteriorização da falange distal e osteíte podal da pinça decorrentes de laminite asséptica.

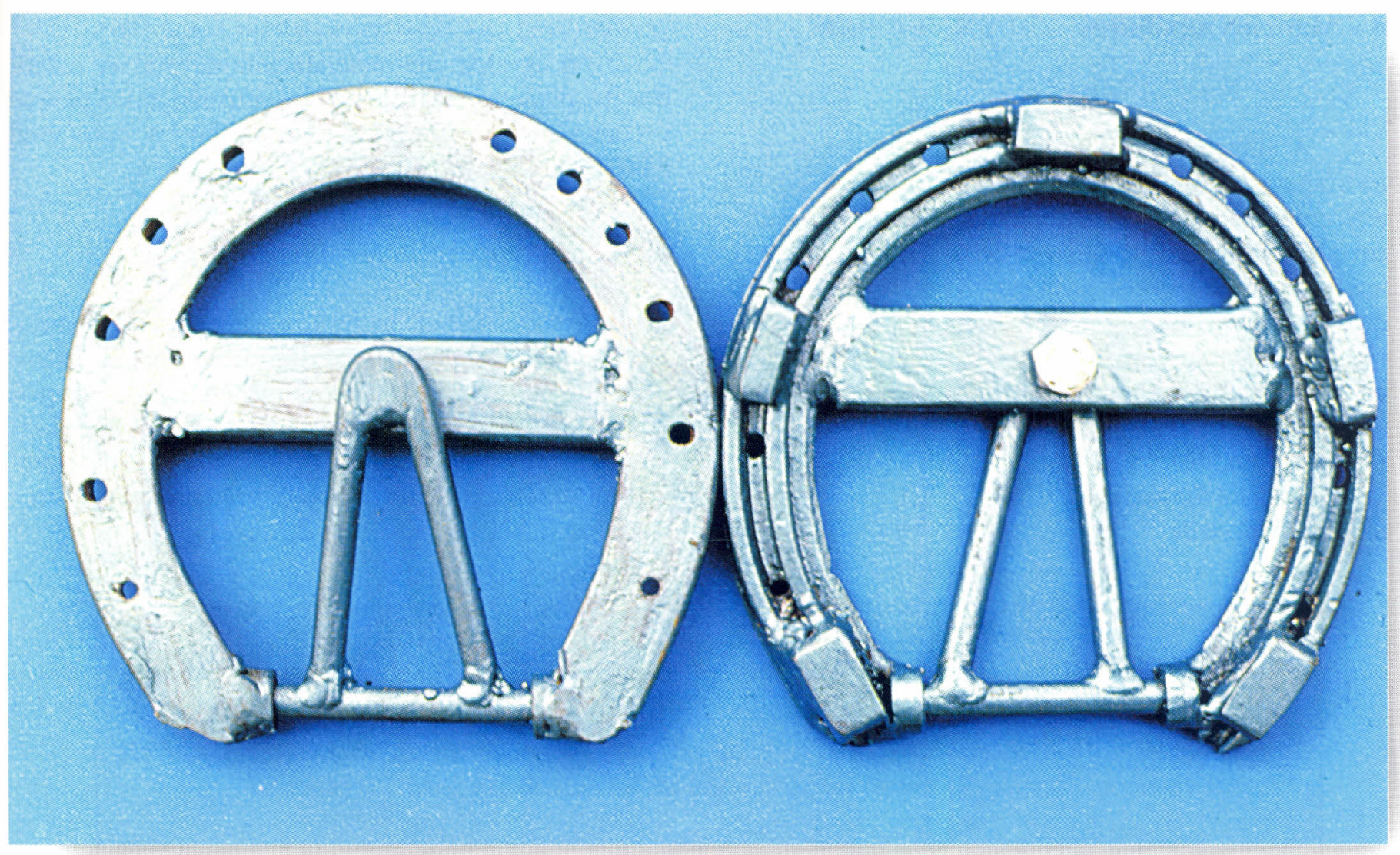

Figura 10. Ferradura tipo coração ("heart-bar"), com regulagem de pressão da ranilha. 
THOMASSIAN, A.; NICOLETTI, J. L. M.; HUSSNI, C.A.; ALVES, A.L.G. Patofisiologia e tratamento da pododermatite asséptica difusa nos eqüinos - (Laminite eqüina) / Laminitis pathophysiology and treatment in horses. Rev. educ. contin. CRMV-SP / Continuous Education Journal CRMV-SP, São Paulo, volume 3, fascículo 2, p. $16-29,2000$.

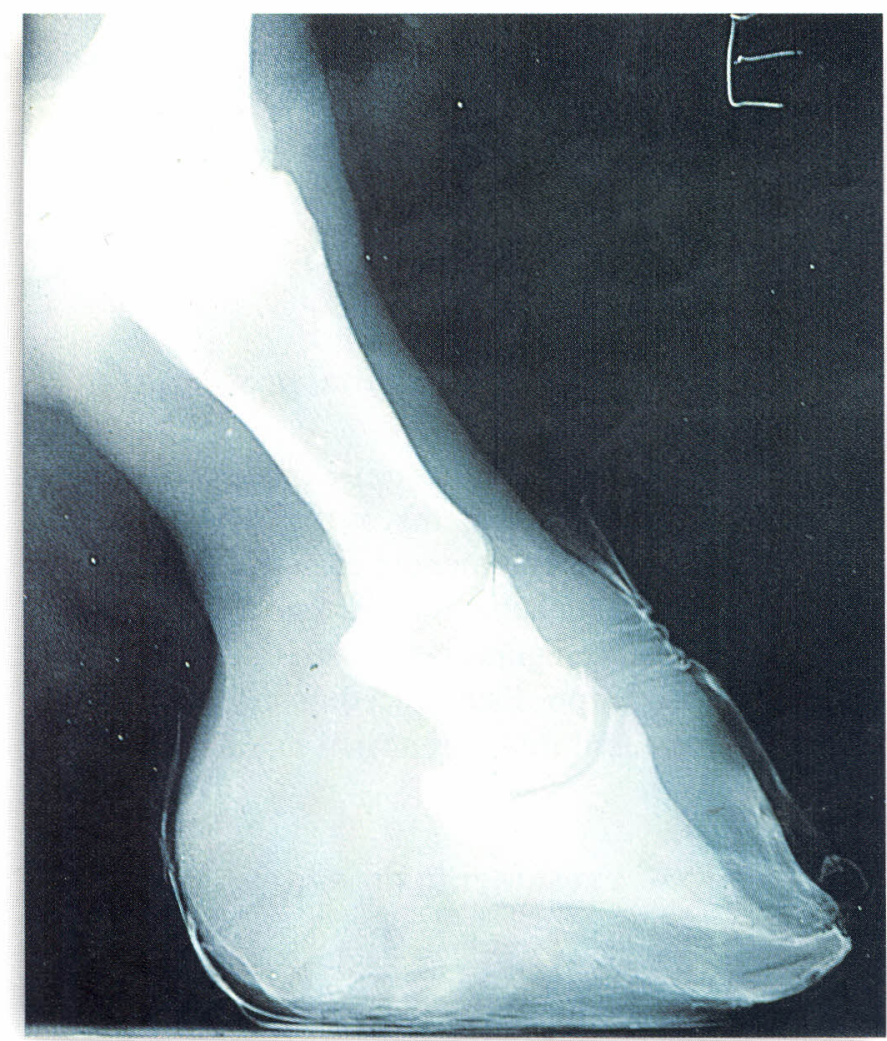

Figura 11. Casqueamento com paralelismo da muralha do casco com a falange distal.

\section{4 - Manejos auxiliares}

\section{Alimentar}

A alimentação de cavalos com laminite deve se restringir à administração de fenos de boa qualidade e a uma mínima quantidade de concentrados, nos quadros em que a etiologia não seja primariamente alimentar. Animais obesos necessitam perder peso até valores considerados aceitáveis para a raça. Paralelamente aos procedimentos terapêuticos gerais e alimentares, pode-se instituir a administração de suplementos tróficos da queratogênese como:

- Metionina: dose de 10 a $30 \mathrm{~g} / \mathrm{dia} / 1$ semana e depois reduzir para $5 \mathrm{~g} / \mathrm{dia} / 3-4$ semanas.

- Biotina: dose de 10 a 20 g/dia, por no mínimo 90 dias.

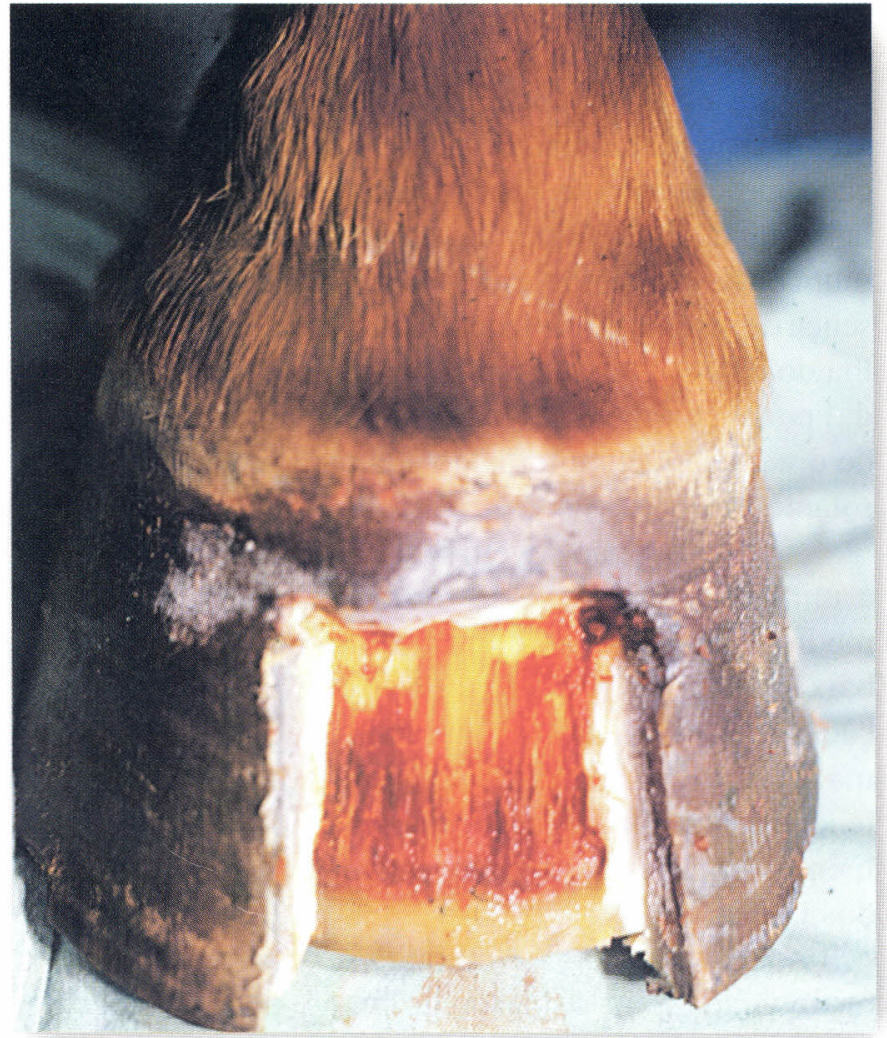

Figura 12. Ressecção parcial da muralha do casco.

Os cavalos preferencialmente devem ser mantidos em piquetes planos e macios, quando ainda permanecem a maior parte do dia em pé, ou em baias com camas altas e macias.

\section{5 - Manejo preventivo}

A prevenção da laminite deve ser realizada basicamente por um controle rigoroso da ingestão de grãos; casqueamento periódico e correto; tratamento adequado a todo processo febril; assistência às éguas que abortaram ou que apresentaram partos distócicos ou retenção de placenta; trabalho e transporte compatíveis com as aptidões físicas e atléticas do cavalo.

\section{SUMMARY}

A severe affection of the locomotor system in horses, laminitis has several aspects discussed in this article, as anatomy, pathophysiology, clinical signs of acute and chronic stages, as well as major procedures used in treatment. Modern surgical procedures for management of the more severe clinical cases or refractory to conservative procedures are also presented.

Key words: horses, locomotor system, lameness, laminitis. 
THOMASSIAN, A.; NICOLETTI, J. L. M.; HUSSNI, C.A.; ALVES, A.L.G. Patofisiologia e tratamento da pododermatite asséptica difusa nos eqüinos - (Laminite eqüina) / Laminitis pathophysiology and treatment in horses. Rev. educ. contin. CRMV-SP / Continuous Education Journal CRMV-SP, São Paulo, volume 3 , fascículo 2, p. $16-29,2000$.

\section{BIBLIOGRAFIA DE APOIO}

1 - ALLEN, D.; WHITE, N.A.; FOERNER, J.F.; GORDON, B.J. Surgical management of chronic laminitis in horses: 13 cases (1983-1985). Journal American Veterinary Medical Association, v. 189, p. 1604-6, 1986.

2 - BAXTER, G.M. Acute laminitis. Veterinary Clinics of North American: Equine Practice. v.10, n.3, p.627-42, 1994.

3 - BAXTER, G.M. Equine laminitis caused by distal displacement of the distal phalanx: 12 cases (1976-1985), Journal American Veterinary Medical Association, v. 189, p. 3269, 1986.

4 - BAXTER, G.M. Laminitis. In: ROBINSON, N.E. Current therapy in equine medicine, 4.ed. Philadelphia: W.B. Saunders, 1997. p.737-43.

5 - BELKNAP, J.K.; MOORE, J.N. Evaluation of heparin for prophylaxis of equine laminitis: 71 cases (1980-1986). Journal American Veterinary Medical Association, v. 195, p. 5057, 1989.

6 - GOETZ, T.E. Anatomic, hoof, and shoeing considerations for the treatment of laminitis in horses. Journal American Veterinary Medical Association, v. 190, p. 1323-32, 1987.

7 - HUNT, R.J. A retrospective evaluation of laminitis in horses. Equine Veterinary Journal, v.25, p. 61-4, 1993.

8 - HUNT, R.J.; ALLEN, D.; BAXTER, G.M.; JACKMAN B.R.; PARKS, A.H. Mid-metacarpal deep digital flexor tenotomy in the management of refractory laminitis in horses. Veterinary Surgery, v.20, p.15-20, 1991.

9 - HUSSNI, C.A.; ALVES, A.L.G.; NICOLETTI, J.L.M.; THOMASSIAN, A. Tenotomia proximal do flexor digital profundo na deformidade flexora em eqüinos. Revista de Educação Continuada do CRMV-SP, v.2, n.3, p. 23-9, 1999.

10 - MOORE, J. N.; ALLEM, D.; CLARK, E.S. Pathophysiology of acute laminitis. Veterinary Clinical of North American: Equine Practice, v.5, p.67-72, 1989.

11 - O'GRADY, S.E. A practical approach to treating laminitis. Veterinary Medicine, v.88, p.867-75, 1993.

12 - RIBEIRO, M.G.; NICOLETTI, J.L.M.; THOMASSIAN, A.; HUSSNI, C.A. Reparação de lesões ósseas perfurantes produzidas experimentalmente na falange distal de eqüinos normais. Revista de Educação Continuada do CRMV-SP, v.2, n.3, p.30-7, 1999.

13 - STICK, J.S.; JANN, H.W.; SCOTT, E.A.; ROBINSON, N.E. Pedal bone rotation as a prognostic sign in laminitis in horses. Journal American Veterinary Medical Association, v. 18 , p. $251-3,1982$.

14 - THOMASSIAN, A. Enfermidades dos cavalos, 3. ed. São Paulo: Varela 1997, 643p.

15 - YELLE, M. Clinician's guide to equine laminitis. Equine Veterinary Journal, v. 18, p. 156-8, 1986.

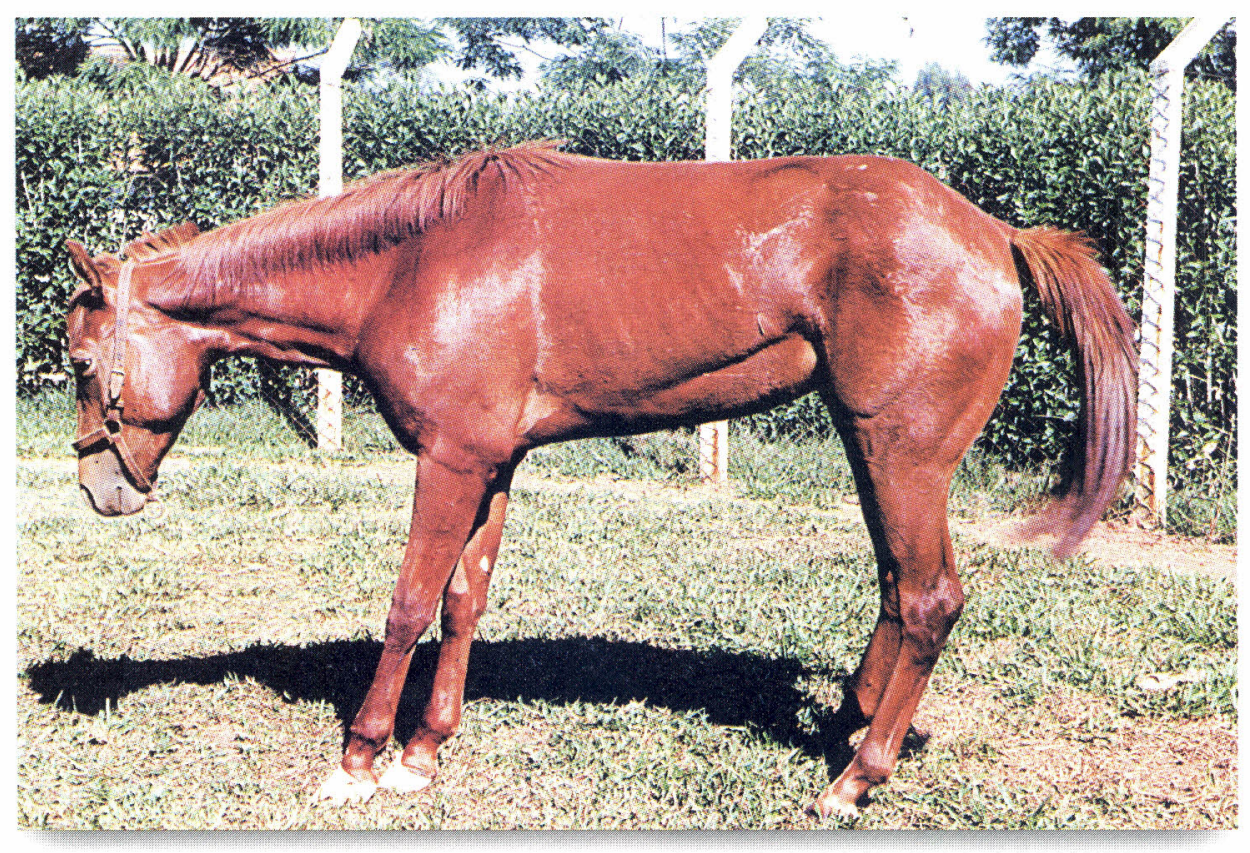

